This is an author produced version of a paper published in Preventive Veterinary Medicine.

This paper has been peer-reviewed but may not include the final publisher proof-corrections or pagination.

Citation for the published paper:

Jan Hultgren, Katarina Arvidsson Segerkvist, Charlotte Berg, Anders H. Karlsson, Bo Algers . (2020) Animal handling and stress-related behaviour at mobile slaughter of cattle. Preventive Veterinary Medicine. Volume: 177, Number: April 2020, pp 1-11.

https://doi.org/10.1016/j.prevetmed.2020.104959

Access to the published version may require journal subscription.

Published with permission from: Elsevier.

Standard set statement from the publisher:

(C) Elsevier, 2020 This manuscript version is made available under the CC-BY-NC-ND 4.0 license http://creativecommons.org/licenses/by-nc-nd/4.0/

Epsilon Open Archive http://epsilon.slu.se 


\title{
Animal handling and stress-related behaviour at mobile slaughter of cattle
}

\author{
Jan Hultgren $^{\mathrm{a} *}$, Katarina Arvidsson Segerkvist ${ }^{\mathrm{b}}$, Charlotte Berg $^{\mathrm{c}}$, Anders H. Karlsson ${ }^{\mathrm{d}}$ and Bo Algers ${ }^{\mathrm{e}}$ \\ abcde Swedish University of Agricultural Sciences, Department of Animal Environment and Health, P.O. Box \\ 234, SE-53223 Skara, Sweden \\ E-mail addresses: ${ }^{\mathrm{a}}$ jan.hultgren@slu.se; b katarina.segerkvist@slu.se; c lotta.berg@slu.se;

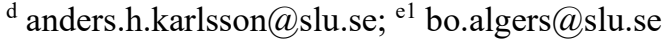 \\ * Corresponding author, E-mail: jan.hultgren@slu.se
}

\begin{abstract}
By avoiding animal transportation, mobile slaughter may have the potential to reduce animal stress. In a crosssectional study with elements of cohort design, we investigated relationships between animal handling and stress-related animal behaviours in connection with slaughter at two Swedish slaughter plants: a newly started small-scale on-farm mobile abattoir and a relatively large-scale stationary slaughterhouse. To the stationary plant, the animals were transported on average $99 \mathrm{~km}$ from farms, and one third of these animals spent one night in lairage before slaughter. Data were collected during processing of 298 animals at both plants during one year. Stockperson actions and animal behaviours were observed in the driveways ( 2.4 to $7.3 \mathrm{~m}$ long) to the stun box. Data on season, hour of day, air temperature, animal breed, animal category, animal age, carcass weight and stockperson category (plant or farm) were also collected. We used Spearman rank correlation, principalcomponent analysis and confirmatory factor analysis to develop a final generalised structural equation model, which contained six variables that represented observed animal backing; turning; slipping; eliminating; vocalising; and violent behaviour, regressed on a latent variable representing animal stress level. Stress level and animal behaviours were also regressed on five variables representing observed stockperson actions (touching, patting or hitting with hand; touching, patting or hitting with a tool; pushing; tail-twisting; and prodding with an electric goad) and on background variables including plant identity. The animal behaviours were modelled as counts per driveway length, clustered on farm identity. Marginal effects of stockperson actions and predictive margins of plants were calculated. The animals displayed backing and violent behaviour (kicking, goring or violent fighting) at significantly lower frequencies at the mobile plant than at the stationary one. In general, stockperson actions were significantly positively associated with animal behaviours, i.e. increased actions were associated with more frequent behaviours. Stockperson moving with tool, pushing and using electric goad were indirectly significantly associated with all animal behaviours via animal stress level. This study shows the importance of adequate cattle handling to limit pre-slaughter stress.
\end{abstract}

Keywords: Animal behaviour, Animal handling, Cattle, Human-animal interaction, Mobile slaughter, Stress

\section{Introduction}

Cattle are transported between different locations for various reasons. The majority of animals are moved from the home farm to a slaughterhouse, where they are killed and processed into meat for human consumption. Each year approximately 0.3 billion cattle are slaughtered for commercial purposes (FAOSTAT, 2017). Some of them are shipped on trucks or trailers to abattoirs nearby, but the slaughterhouse is sometimes far from the home farm and the nearest facility is not always preferred.

Due to a massive restructuration of livestock husbandry and food production, journeys from farm to plant may become longer (Bench et al., 2008) and the number of animals slaughtered per time unit (the line speed) may increase. Average herd sizes increase and labour is automated, which decreases the amount of human-animal interaction (Raussi, 2003) and may lower the animals' tolerance to preslaughter handling (Waiblinger et al., 2006; Bunzel-Drüke et al., 2009). Innovative methods for decentralised slaughter and meat processing can help enable small livestock producers to market products to consumers in their region or community (Johnson et al., 2012; Gwin and Thiboumery, 2014). Lambooij et al. (2011) published a survey to investigate possibilities for mobile slaughter of

\footnotetext{
${ }^{1}$ Present address: Skarviksvägen 17A, SE-47537 Bohus-Björkö, Sweden
} 
livestock and poultry, and concluded that it may have advantages for small-scale producers, which was supported by e.g. Angioloni et al. (2015).

A mobile slaughter plant is a self-contained processing unit that can be moved between farms. Slaughter can take place on any farm of sufficient size to house the plant, and transportation of the animals is avoided. Livestock, reindeer and poultry are slaughtered in mobile plants in several countries, but the total volume of mobile slaughter is not known. EU legislation allows mobile slaughter of all kinds of domestic animals (Council Regulation No 1099/2009). According to Johnson et al. (2012) a mobile cattle facility can typically process 5-10 head per day. Stunning of livestock may take place in a pen outside the plant, or in a specially designed stun box inside the plant.

The consequences of mobile slaughter for animal welfare have so far not been studied scientifically to any greater extent. Norwegian researchers found signs of reduced stress in lambs slaughtered in a mobile plant, compared to a large-scale industrial plant, as indicated by lowered blood glucose levels (Skog Eriksen et al., 2013). Although animal transport on road is largely avoided in mobile slaughter, the short walk from the housing facilities to the point of stunning may still be detrimental to animal welfare, if driveways are not adequately designed and stockpersons are not sufficiently trained.

In this paper, we report on an observational study of stress-related behaviour during pre-slaughter handling of cattle in a mobile slaughter plant, comparing with a stationary plant. The mobile plant was contained in two trucks with trailers. We hypothesised that stress-related cattle behaviours during preslaughter handling are less frequent at the mobile than at the stationary plant, that stress-related behaviours are more frequent in an animal subjected to many handling actions by stockpersons, compared to few such actions, and that associations between stockperson actions and animal behaviours are to some extent mediated by a common (unobserved) quantity which could be regarded as the animal's stress level.

\section{Material and methods}

\subsection{Slaughter plants and animals}

Cattle slaughter at a Swedish mobile unit was compared to slaughter at a Swedish large-scale stationary plant. The mobile plant was the only commercial facility in Sweden, in operation since the end of 2014, and the stationary plant was selected because it agreed to participate. The mobile plant and its cooling facility were housed in two trucks with trailers, also described by Hultgren (2018). The line speed was approximately 4 animals per hour or 30-35 animals per day in the mobile unit, and 4550 animals per hour or 290-320 animals per day in the stationary plant. At each plant, 298 animals were studied.

At the mobile plant, the animals were brought on foot from the housing facilities to an inspection pen just outside the plant, where they were gathered in groups of up to about five animals before being moved into the stun box, which was placed in the rearmost part of one of the trailers. The single-file driveway between the inspection pen and stun box was straight and 2.4 to 5.7 (mean 4.9) $\mathrm{m}$ long, depending on the layout of the yard, and temporarily mounted directly on the ground. The walls of the driveway were made of metal pipes, which were occasionally covered by solid boards. The driveway was limited at the rear by a sliding gate at the exit from the inspection pen, and at the front by a guillotine gate at the entrance to the stun box. There was also a sliding gate about halfway in the driveway. The animals were moved in the driveway by farm staff $(n=199)$, plant staff $(n=25)$ or both $(n=74)$.

At the stationary plant, the animals were transported on road from the farm (mean \pm sd $99 \pm 58 \mathrm{~km}$ ) and slaughtered on arrival, or kept in lairage for some time, with access to water. Ninety-six animals were transported on the day before slaughter and kept in lairage overnight in single or group boxes, with access to both feed and water. At the time of slaughter, the animals were moved up to the stun box. Observations took place in the last $7.3 \mathrm{~m}$ of the driveway before the entrance to the stun box. The observed part of the driveway was straight and limited by guillotine gates at the rear and front. There was also a guillotine gate halfway. The floor was equipped with rubber mat with small amounts of sawdust and the walls were solid. 


\subsection{Animals}

The animal was the unit of observation. At the mobile plant, we observed 8-21 animals per day for 17 days between February 2016 and March 2017. Observations took place at slaughter on 15 farms in southern and central Sweden. On two of the farms, observations were made on two days. Only animals that were delivered from the farm where the plant was parked during slaughter were included in the study. At the stationary plant, observations of 10-25 animals per day were carried out for 17 days between April 2016 and February 2017. The animals had been delivered from 144 farms (1-10 studied animals per farm) located on average $99 \mathrm{~km}$ from the plant. Study days were selected as evenly as possible over the year, without regard to variations in slaughterhouse activities or animal material.

On study days, as many animals as practically possible were sampled. All data collection from one animal (up to and including carcass weight) was completed before observation of a new animal was started (in the driveway to the stun box). The first animal that was available then was chosen, without regard to the type of cattle. This procedure meant that a large number of animals were slaughtered without being observed, especially at the stationary plant. It was estimated that 89 and $9.8 \%$ of the animals slaughtered during observation hours at the mobile and stationary plant, respectively, were sampled. The studied animals were considered to be a representative sample from each plant.

\subsection{Observations}

Two research technicians performed all observations. One of them stood beside the driveway, i.e. outside the mobile but inside the stationary plant, and recorded all stockperson actions and animal behaviours. The other technician recorded carcass weights.

For each animal, the numbers of handling actions listed in Table 1 were recorded by direct continuous observations in the driveway by the technician. It was noted whether the actions were performed with the body (normally, hands) or with a tool. At both plants, a plastic sorting paddle was the most common tool, but a plastic pipe was sometimes used at the mobile plant. A total of eight stockpersons handled the animals in the driveway at the mobile plant and six stockpersons at the stationary plant. At the mobile plant, the stockpersons often entered the inspection pen and driveway when moving the animals through the driveway, which rarely happened at the stationary plant.

Table 1

Observed stockperson handling actions in the driveway.

\begin{tabular}{ll}
\hline Action & Description \\
\hline Touch rear & Touch animal lightly behind withers \\
Touch front & Touch animal lightly in front of withers \\
Pat rear & Pat animal behind withers with arm bent in wrist or elbow but not shoulder \\
Pat front & Pat animal in front of withers with arm bent in wrist or elbow but not shoulder \\
Hit rear & Hit animal behind withers with arm bent in shoulder \\
Hit front & Hit animal in front of withers with arm bent in shoulder \\
Pull & Pull or dragg animal in any body part using hand or tool \\
Push & Push or shove the animal using hand or tool \\
Prod & Prod the animal with a sharp tool \\
Hold & Hold or restrain animal in any body part using hand or tool \\
Tail-twist & Twist tail with hand \\
Wave & Wave arm or tool without touching animal \\
Kick & Kick animal in any body part \\
Gate-hit & Hit the animal with a gate (from side or from above) \\
Electric goad & Prod with electric goad on animal behind withers \\
Shout & Speak, shout ot whistle \\
Slam & Produce sound by hitting or slamming fittings with hand or tool \\
\hline
\end{tabular}


Likewise, the numbers of stress-related animal behaviours listed in Table 2 were recorded by direct continuous observations in the driveway, as well as the time in the driveway, measured by the technician's wristwatch. Recorded background variables represented slaughter plant (Plant: mobile; stationary), season (Season: spring - Feb.-May 2016; summer - Jun.-Aug.; autumn - Sep.-Nov.; winter - Dec. 2016-Mar. 2017), hour of day (Hour: morning - 06:30-09:59; day - 10:00-18:00), ambient air temperature in driveway $\left(\boldsymbol{T e m p},{ }^{\circ} \mathrm{C}\right)$, animal breed type (Breed: beef; dairy or mixed dairy-beef), animal category (Animcat: bull; steer, cow; heifer), animal age (Age, months) and carcass weight (Cweight, $\mathrm{kg})$. Specific breed was not recorded.

Table 2

Observed stress-related animal behaviours in the driveway or stun box.

\begin{tabular}{ll}
\hline Behaviour & Description \\
\hline Back & Back at least two steps \\
Run & Move forward in trot or gallop \\
Trip & Trip or pitter-patter with quick steps without moving forward, without stumbling \\
Turn & Turn head or body backwards \\
Stumble & Stumble or slip, without losing gait rhythm, without lower legs or body touching \\
& ground \\
Slip & Stumble or slip, losing gait rhythm, possibly with lower legs but without body touching \\
& ground \\
Fall & Fall with body touching ground \\
Kick & Kick towards stockperson, other animal or fittings \\
Gore & Gore or butt towards stockperson, other animal or fittings \\
Drop & Defecate or urinate \\
Vocalise & Bellow \\
Fight & Fight violently, throwing itself against fittings \\
Freeze & Freeze, stand still \\
\hline
\end{tabular}

\subsection{Statistical analysis}

Stockperson actions (Table 1) were grouped to form variables named Hand (denoting touch rear, touch front, pat rear, pat front, hit rear or hit front with hand), Tool (touch rear, touch front, pat rear, pat front, hit rear or hit front with tool), Push, Nois (shout or slam), Tail (tail-twist) or Goad (electric goad). Stockperson actions were regarded as continuous variables, representing counts of actions per study animal. Actions describing pulling, prodding, holding waving, kicking and gate-hitting (Table 1) occurred rarely and were not included as variables. Similarly, animal behaviours (Table 2) were grouped and named Back, Turn, Slip (stumble, slip or fall), Drop, Vocl (vocalise) or Viol (kick, gore, butt or fight). Behaviours describing running and tripping (Table 2) occurred rarely and were not included as variables. The observations of freezing were regarded less reliable and were therefore not included either. In the following analytical steps, continuous background variables (Temp, Age and Cweight were initially tested as polynomial extentions to the second degree to check for curvilinear relationships (i.e. testing both the squared non-squared variables but retaining the squared ones only if significant).

The main part of the statistical analysis was made in Stata/IC 15 (StataCorp, College Station, Texas, USA) with the animal as the unit of analysis. The influence of the observed stockperson actions and background variables on stress-related animal behaviour was investigated by Structural Equation Modelling (SEM; Acock et al., 2013). The final model consisted of a measurement part with the six observed animal behaviours (indicators) that were regressed on a latent variable Stress, and a structural part describing relationships between exogenous variables (stockperson actions and background variables) and endogenous variables (Stress and animal behaviours). Hence the behaviours displayed by the animal being moved were regarded as indicators of an unobserved mental state reflected by a tendency of the animal to show the recorded behaviours.

The intention was to model animal behaviour variables as counts, also accounting for farm clustering by introducing the random effect Farm $(n=159)$. This required use of a generalised SEM approach (Stata gsem command) and maximum-likelihood estimation. However, during the 
development of the SEM, the behaviours were at times expressed as continuous variables to allow the ordinary SEM approach (Stata sem command), which assumed Normal endogenous variables and no random effects, and to generate model diagnostics. To achieve this, the behaviour variables were standardised by dividing the counts by either the driveway length (in metres) or the time for passing the driveway (in minutes). In the final model, animal behaviours were modelled as raw counts (assumed to follow negative binomial distributions) which expressed the number of behaviours shown by an animal while being moved from the inspection pen to the stun box, using length of the driveway as the exposure parameter (or, equivalently, its logarithm as offset). The corresponding resulting model estimates were interpreted as incidence risk ratios (IRRs).

Firstly, the measurement model was constructed and evaluated by Confirmatory Factor Analysis (CFA; Brown, 2015). In this step, animal behaviours were initially specified as counts standardised for driveway length or time (using ordinary SEM and an asymptotic distribution-free estimation method, appropriate when latent variables and their errors are not normally distributed), and later as raw counts (assumed to follow negative binomial distributions with driveway length as exposure parameter) adding producer farm as random factor (requiring generalised SEM). Associations between the behaviours were investigated with Spearman rank correlation and Principal Component Analysis (PCA). As measures of internal consistency and model reliability we used Cronbach's alpha (Cronbach, 1951), McDonald's omega (McDonald, 1999) and the Greatest Lower Bound (Bentler and Woodward, 1980), obtained with Stata and JASP software version 0.9.2 (University of Amsterdam, Amsterdam, Netherlands).

Secondly, a Multiple-Indicators-Multiple-Causes model (Jöreskog \& Goldberger, 1975) was constructed by introducing variables representing stockperson actions, selected through backward elimination. As before, the animal behaviours were specified as continuous variables that were standardised by driveway length (ordinary SEM). Direct paths from stockperson actions to animal behaviours were added if statistically significant $(p \leq 0.05)$ and non-significant paths from actions to Stress were deleted, until an acceptable model fit was achieved. Model fit was assessed using the model versus the saturated model Chi-square test ( $p>0.05$ regarded as acceptable), the root mean squared error of approximation (RMSEA; Browne and Cudeck, 1993) and its confidence interval (values $<0.05$ with the upper bound of the $90 \%$ confidence interval $<0.10$ regarded as acceptable), the comparative fit index (CFI; Bentler, 1990) $(>0.95)$, and the standardised root mean squared residual (SRMR; Hancock and Mueller; 2006) $(<0.08)$.

Thirdly, background variables were tested one at the time and jointly, selected by backward elimination and retaining only significant variables $(p \leq 0.05)$. Direct paths from background variables to animal behaviours were also tested, until all paths were significant and the model fit was acceptable, using the criteria mentioned above. At this stage, a complete SEM with a reasonable fit was obtained, although the animal behaviours were expressed as continuous variables, standardised by driveway length, and clustering by farm was disregarded.

Finally, the behaviours were specified as counts assumed to follow negative binomial distributions and the random $\boldsymbol{F a r m}$ effect was introduced, applying the generalised SEM approach. To achieve model convergence, we used the mean-and-variance adaptive Gauss-Hermite quadrature method (Rabe-Hesketh et al., 2005) and seven integration (quadrature) points. The model was adjusted stepwise by adding and deleting paths until convergence was reached and all paths were significant. Due to convergence difficulties, it was not possible to include interaction effects in the model. Unstandardised coefficients of direct, indirect and total effects of stockperson actions on animal behaviours were calculated. Effects of background variables (including Plant) were interpreted as causal relationships. In contrast, it was not possible to determine direction of the effects of stockperson actions (because actions and animal behaviours were probably interdependent and it was our choice to specify the behaviours as dependent variables), so these were merely interpreted as statistical associations.

Based on the final SEM, predictive margins were calculated and graphed. Predictive margins were statistics calculated from predictions at fixed values of exogenous variables, such as the predicted numbers of an animal behaviour at the mobile and stationary plants or at different numbers of stockperson actions. Furthermore, marginal effects (predicted derivatives at given values of a continuous exogenous covariate) were calculated to test the average change in the number of animal behaviours per extra stockperson action. The predictive margins and marginal effects were calculated 
while assuming observed values of the remaining covariates in the model. The effect of Plant was tested at different levels of other exogenous variables using pairwise comparisons of selected predictive margins. Standard errors were obtained by the delta method (Oehlert, 1992).

\section{Results}

Table 3 shows summary statistics for stockperson actions, continuous background variables and animal behaviours at the mobile and stationary plants. All actions and behaviours, as well as standardised behaviours, were heavily skewed. Table 4 shows summary statistics for categorical background variables. At both plants, the most commonly occurring action was $\mathbf{T o o l}$ and the most common behaviour Back (49-59 and 68-85\% of animals, respectively). Pushing and tail-twisting were considerably more common at the mobile plant, while the opposite was true for using the electric goad. Regarding animal behaviours, eliminative behaviour was more common at the mobile plant, but vocalisations at the stationary. Most animals were handled actively in the driveway, although stockperson actions were slightly less common at the mobile plant; the percentage of animals not receiving any stockperson action in the driveway was $9.4 \%$ at the mobile plant and $3.0 \%$ at the stationary. Likewise, most animals displayed one or several stress-related behaviours, although these behaviours were less common at the mobile plant; the percentage not showing any stress-related behaviour was $28.9 \%$ at the mobile and $11.7 \%$ at the stationary plant. The time in the driveway was 0.08-38.1 (mean 3.67) minutes at the mobile and 0.10-17.7 (mean 2.54) minutes at the stationary plant. It was noted that loud noise from inside the mobile plant (saw noise, staff shouting) sometimes disturbed the animals waiting outside, thereby making driving to the shooting box difficult.

At the mobile plant, the studied animals were to a larger extent of beef breed, and there were more steers and heifers and less cows, than at the stationary plant (Table 4). Animals categorised as bulls were almost invariably young fattening bulls, slaughtered at the average age of 17.5 months at the mobile plant and 20.2 months at the stationary (not in table). Only two older breeding bulls were included; they were slaughtered at the stationary plant at the age of 38 months and categorised as bulls. The largest difference between the plants in the proportion of animals of beef breed was found for steers, with 38 and $7 \%$ at the mobile and stationary plant, respectively (not in table).

Table 5 shows rank correlations for the animal behaviour variables, expressed as raw counts and counts standardised by driveway length and time in driveway. Most correlations were weak or moderate (Spearman rho $<0.52,<0.54$ and $<0.22$, respectively). In the PCA of raw counts and counts standardised for driveway length, one factor had an eigenvalue above 1, explaining 33.9 and $34.4 \%$ of the variation, respectively. For the variables standardised for time in driveway, three factors had eigenvalues above 1, explaining 23.2, 20.1 and $16.8 \%$ of the variation. First-factor loadings were $0.35-0.83,0.28-0.84$ and $-0.056-0.64$ for raw counts, counts standardised for driveway length, and counts standardised for time in driveway, respectively (Table 6). For all three variants, the likelihoodratio test of the independent versus saturated model was significant (Chi-square (15 d.f.) $=399.6 ; 439.9$ and 103.8, respectively; $p=0.0005)$. The reliability of the measurement model was barely acceptable, using raw behaviour counts and counts standardised for length of driveway (Table 7). Correlations and PCA factor loadings indicated that standardisation for driveway length was the most useful variant of animal behaviour variables, followed by raw counts. Consequently, in the following analytical steps, the animal behaviours were either specified as continuous variables standardised for driveway length (using ordinary SEM) or as counts assumed to follow negative binomial distributions with driveway length as the exposure parameter (using generalised SEM). 
Table 3

Summary statistics of stockperson actions, continuous background variables and animal behaviours at the mobile and stationary plants $(n=298)$.

\begin{tabular}{|c|c|c|c|c|c|c|}
\hline Variable & Plant & Above $0^{1}(\%)$ & Mean & Median & IQR or $\mathrm{sd}^{2}$ & Max \\
\hline \multirow[t]{2}{*}{ Hand } & Mobile & 59.1 & 8.24 & 2 & 8 & 18 \\
\hline & Stationary & 49.3 & 3.34 & 0 & 4 & 43 \\
\hline \multirow[t]{2}{*}{ Tool } & Mobile & 48.3 & 9.19 & 0 & 9 & 191 \\
\hline & Stationary & 77.2 & 9.85 & 5 & 14 & 79 \\
\hline \multirow[t]{2}{*}{ Push } & Mobile & 27.2 & 0.537 & 0 & 1 & 6 \\
\hline & Stationary & 0.67 & 0.0067 & 0 & 0 & 1 \\
\hline \multirow[t]{2}{*}{ Nois } & Mobile & 67.8 & 4.59 & 2 & 5 & 68 \\
\hline & Stationary & 59.1 & 3.35 & 2 & 4 & 38 \\
\hline \multirow[t]{2}{*}{ Tail } & Mobile & 20.5 & 0.500 & 0 & 0 & 12 \\
\hline & Stationary & 3.02 & 0.054 & 0 & 0 & 5 \\
\hline \multirow[t]{2}{*}{ Goad } & Mobile & 11.7 & 0.705 & 0 & 0 & 35 \\
\hline & Stationary & 20.1 & 0.664 & 0 & 0 & 16 \\
\hline \multirow[t]{2}{*}{ Any action } & Mobile & 90.6 & 23.8 & 9 & 22 & 289 \\
\hline & Stationary & 97.0 & 17.3 & 9 & 19 & 102 \\
\hline \multirow[t]{2}{*}{ Temp, ${ }^{\circ} \mathrm{C}$} & Mobile & - & 9.48 & 6.9 & 9.38 & 26.8 \\
\hline & Stationary & - & 12.5 & 11.0 & 5.08 & 22.0 \\
\hline \multirow[t]{2}{*}{ Age, months } & Mobile & - & 28.2 & 23 & 22.1 & 178 \\
\hline & Stationary & - & 34.9 & 25 & 27.0 & 177 \\
\hline \multirow[t]{2}{*}{ Cweight, kg } & Mobile & - & 344 & 339 & 44.2 & 482 \\
\hline & Stationary & - & 345 & 339 & 68.4 & 633 \\
\hline \multirow[t]{2}{*}{ Back } & Mobile & 67.8 & 2.70 & 1 & 4 & 14 \\
\hline & Stationary & 84.6 & 3.23 & 3 & 4 & 19 \\
\hline \multirow[t]{2}{*}{ Turn } & Mobile & 35.9 & 1.31 & 0 & 2 & 15 \\
\hline & Stationary & 37.2 & 0.889 & 0 & 1 & 9 \\
\hline \multirow[t]{2}{*}{ Slip } & Mobile & 9.73 & 0.178 & 0 & 0 & 9 \\
\hline & Stationary & 10.7 & 0.144 & 0 & 0 & 4 \\
\hline \multirow[t]{2}{*}{ Drop } & Mobile & 26.2 & 0.346 & 0 & 1 & 3 \\
\hline & Stationary & 10.4 & 0.107 & 0 & 0 & 2 \\
\hline \multirow[t]{2}{*}{ Vocl } & Mobile & 10.7 & 0.466 & 0 & 0 & 22 \\
\hline & Stationary & 27.5 & 1.25 & 0 & 1 & 37 \\
\hline \multirow[t]{2}{*}{ Viol } & Mobile & 13.8 & 0.319 & 0 & 0 & 12 \\
\hline & Stationary & 19.8 & 0.436 & 0 & 0 & 9 \\
\hline \multirow[t]{2}{*}{ Any behaviour } & Mobile & 71.1 & 5.32 & 2 & 8 & 42 \\
\hline & Stationary & 88.3 & 6.06 & 5 & 6 & 49 \\
\hline
\end{tabular}

${ }^{1}$ Percentage of animals in which the action or behaviour was observed at least once.

${ }^{2}$ Inter-quartile range for actions and behaviours; standard deviation for continuous background variables. 
Table 4

Summary statistics of categorical background variables at the mobile and stationary plants.

\begin{tabular}{|c|c|c|c|c|c|}
\hline \multirow[b]{2}{*}{ Variable } & \multirow[b]{2}{*}{ Level } & \multicolumn{2}{|c|}{ Mobile } & \multicolumn{2}{|c|}{ Stationary } \\
\hline & & $n$ & $\%$ & $n$ & $\%$ \\
\hline \multirow[t]{4}{*}{ Season } & Spring & 69 & 23.2 & 52 & 17.5 \\
\hline & Summer & 94 & 31.5 & 104 & 34.9 \\
\hline & Autumn & 58 & 19.5 & 41 & 13.8 \\
\hline & Winter & 77 & 25.8 & 101 & 33.9 \\
\hline \multirow[t]{2}{*}{ Hour } & Morning & 105 & 35.2 & 162 & 54.4 \\
\hline & Day & 193 & 64.8 & 136 & 45.6 \\
\hline \multirow[t]{2}{*}{ Breed } & Beef & 193 & 64.8 & 139 & 46.6 \\
\hline & Dairy & 105 & 35.2 & 159 & 53.4 \\
\hline \multirow[t]{4}{*}{ Animcat } & Bull & 126 & 42.3 & 122 & 40.9 \\
\hline & Steer & 61 & 20.5 & 28 & 9.40 \\
\hline & Cow & 33 & 11.1 & 94 & 31.5 \\
\hline & Heifer & 78 & 26.2 & 54 & 18.1 \\
\hline
\end{tabular}

Table 5

Correlation matrix of animal behaviour counts (top) and counts standardised for driveway length (middle) and time in driveway (bottom); Spearman rank correlation coefficients; $(n=591)$.

\begin{tabular}{|c|c|c|c|c|c|}
\hline & Back & Turn & Slip & Drop & Vocl \\
\hline \multirow[t]{3}{*}{ Turn } & 0.516 & 1 & - & - & - \\
\hline & 0.536 & 1 & - & - & - \\
\hline & 0.222 & 1 & - & - & - \\
\hline \multirow[t]{3}{*}{ Slip } & 0.204 & 0.180 & 1 & - & - \\
\hline & 0.201 & 0.183 & 1 & - & - \\
\hline & 0.043 & 0.123 & 1 & - & - \\
\hline \multirow[t]{3}{*}{ Drop } & 0.251 & 0.282 & 0.151 & 1 & - \\
\hline & 0.287 & 0.298 & 0.154 & 1 & - \\
\hline & 0.003 & 0.208 & 0.109 & 1 & - \\
\hline \multirow[t]{3}{*}{ Vocl } & 0.240 & 0.239 & 0.092 & 0.101 & 1 \\
\hline & 0.208 & 0.225 & 0.094 & 0.095 & 1 \\
\hline & 0.109 & 0.204 & 0.081 & 0.082 & 1 \\
\hline \multirow[t]{3}{*}{ Viol } & 0.276 & 0.125 & 0.087 & 0.009 & 0.108 \\
\hline & 0.271 & 0.130 & 0.088 & 0.012 & 0.107 \\
\hline & 0.179 & 0.081 & 0.070 & -0.015 & 0.099 \\
\hline
\end{tabular}

Table 6

Factor loadings from principal component analysis (pattern matrix and variance uniqueness).

\begin{tabular}{|c|c|c|c|c|c|c|c|c|}
\hline \multirow[b]{2}{*}{ Variable } & \multicolumn{2}{|c|}{ Raw counts } & \multicolumn{2}{|c|}{$\begin{array}{l}\text { Standardised for } \\
\text { driveway length }\end{array}$} & \multicolumn{4}{|c|}{ Standardised for time in driveway } \\
\hline & Factor 1 & Uniqueness & Factor 1 & Uniqueness & Factor 1 & Factor 2 & Factor 3 & Uniqueness \\
\hline Back & 0.734 & 0.461 & 0.779 & 0.394 & 0.531 & 0.312 & 0.071 & 0.615 \\
\hline Turn & 0.829 & 0.313 & 0.842 & 0.292 & 0.495 & 0.531 & 0.061 & 0.470 \\
\hline Slip & 0.451 & 0.797 & 0.409 & 0.832 & 0.269 & 0.590 & -0.368 & 0.444 \\
\hline Drop & 0.555 & 0.692 & 0.610 & 0.628 & -0.056 & 0.242 & 0.917 & 0.098 \\
\hline Vocl & 0.423 & 0.821 & 0.279 & 0.922 & 0.617 & -0.443 & 0.157 & 0.399 \\
\hline Viol & 0.347 & 0.879 & 0.361 & 0.870 & 0.642 & -0.469 & -0.023 & 0.368 \\
\hline
\end{tabular}


Table 7

Measures of reliability of measurement model of animal stress level based on raw animal behaviour counts and counts standardised for driveway length and time.

\begin{tabular}{lccc}
\hline Variant of counts & Cronbach's alpha & McDonald's omega & Greatest Lower Bound \\
\hline Raw & 0.517 & 0.508 & 0.733 \\
Standardised for driveway length & 0.529 & 0.611 & 0.728 \\
Standardised for time in driveway & 0.287 & 0.310 & 0.434 \\
\hline
\end{tabular}

Table 8 shows CFA results of the measurement model, specifying animal behaviours as raw counts. The estimates were obtained by negative binomial regression, including a random $\boldsymbol{F a r m}$ effect. All paths were significant at $p<0.0005$, except the effect of Stress on slipping behaviour which was non-significant. Turning and eliminative behaviour were close to Poisson distribution (alpha 0.034 and $6.1 \times 10^{-6}$, respectively), while vocalisation displayed the largest over-dispersion (alpha 93), indicating that a low number of animals vocalised many times.

Table 8

Measurement model of Stress with behaviours specified as raw counts and including a random Farm effect $(n=596) ;$ unstandardised coefficients.

\begin{tabular}{rlllll}
\hline Outcome & Predictor & Coefficient & SE & \multicolumn{1}{c}{$p$ value } & \multicolumn{1}{c}{$95 \%$ confidence interval } \\
\hline Back & Intercept & -1.07 & 0.0724 & $<0.0005$ & $(-1.21,-0.928)$ \\
& Farm & $1^{1}$ & - & - & - \\
& Stress & 0.558 & 0.0926 & $<0.0005$ & $(0.376,0.740)$ \\
Turn & Intercept & $-2,67$ & 0.173 & $<0.0005$ & $(-3.01,-2.33)$ \\
& Farm & 1.72 & 0.168 & $<0.0005$ & $(1.39,2.05)$ \\
& Stress & $1^{1}$ & - & - & - \\
Slip & Intercept & -4.64 & 0.267 & $<0.0005$ & $(-5.16,-4.12)$ \\
& Farm & 2.62 & 0.431 & $<0.0005$ & $(1.78,3.47)$ \\
& Stress & 0.090 & 0.146 & 0.54 & $(-0.195,0.376)$ \\
Drop & Intercept & -3.81 & 0.157 & $<0.0005$ & $(-4.12,-3.50)$ \\
& Farm & 1.63 & 0.217 & $<0.0005$ & $(1.21,2.06)$ \\
& Stress & 0.480 & 0.108 & $<0.0005$ & $(0.268,0.693)$ \\
Vocl & Intercept & -2.55 & 0.185 & $<0.0005$ & $(-2.91,-2.19)$ \\
& Farm & 1.42 & 0.362 & $<0.0005$ & $(0.712,2.13)$ \\
& Stress & 0.765 & 0.173 & $<0.0005$ & $(0.426,1.10)$ \\
Viol & Intercept & -3.22 & 0.167 & $<0.0005$ & $(-3.55,-2.90)$ \\
& Farm & 1.00 & 0.273 & $<0.0005$ & $(0.469,1.54)$ \\
& Stress & 0.705 & 0.176 & $<0.0005$ & $(0.361,1.05)$ \\
\hline
\end{tabular}

${ }^{1}$ Coefficient constrained to 1 .

Table 9 and Fig. 1 show final model estimates. All paths were at least marginally significant $(p \leq 0.10)$. Coefficient estimates can be interpreted as change in log number of behaviours per animal per mean driveway length for a 1-unit increase of the predictor, i.e. the exponentiated coefficient is the IRR standardised to the average driveway length in the data $(6.08 \mathrm{~m})$. Turning and eliminative behaviours were close to Poisson distribution (alpha 0.069 and $2.5 \times 10^{-7}$, respectively), while vocalisation again displayed the largest over-dispersion (alpha 6.8). Table 10 shows the marginal effects of stockperson actions on animal behaviours, i.e. the expected average change in number of behaviours for every extra action. 
Table 9

Final generalised structural equation model with stockperson actions and animal behaviours specified as raw counts, using driveway length (in metres) as exposure parameter and including a random Farm effect ( $n=591)$; unstandardised coefficients.

\begin{tabular}{|c|c|c|c|c|c|}
\hline Outcome & Predictor & Coefficient & SE & $p$ value & $95 \%$ confidence interval \\
\hline Back & $\begin{array}{l}\text { Intercept } \\
\text { Hand } \\
\text { Animcat: } \text { steer } \\
\text { Animcat: cow } \\
\text { Animcat: heifer } \\
\text { Plant: } \text { stationary } \\
\text { Farm } \\
\text { Stress }\end{array}$ & $\begin{array}{l}-0.726 \\
0.0049 \\
-0.228 \\
-0.736 \\
-0.417 \\
0.491 \\
1^{1} \\
1^{1}\end{array}$ & $\begin{array}{l}0.258 \\
0.0021 \\
0.128 \\
0.106 \\
0.105 \\
0.103 \\
- \\
-\end{array}$ & $\begin{array}{l}0.005 \\
0.020 \\
0.075 \\
<0.0005 \\
<0.0005 \\
<0.0005 \\
- \\
-\end{array}$ & $\begin{array}{l}(-1.23,-0.221) \\
(0.0008,0.0091) \\
(-0.480,0.023) \\
(-0.944,-0.528) \\
(-0.623,-0.211) \\
(0.289,0.694) \\
- \\
-\end{array}$ \\
\hline Turn & $\begin{array}{l}\text { Intercept } \\
\text { Goad } \\
\text { Farm } \\
\text { Stress }\end{array}$ & $\begin{array}{l}-1.79 \\
-0.120 \\
1^{1} \\
2.41\end{array}$ & $\begin{array}{l}0.566 \\
0.032 \\
- \\
0.202\end{array}$ & $\begin{array}{l}0.002 \\
<0.0005 \\
- \\
<0.0005\end{array}$ & $\begin{array}{l}(-2.90,-0.685) \\
(-0.184,-0.057) \\
- \\
(2.01,2.80)\end{array}$ \\
\hline Slip & $\begin{array}{l}\text { Intercept } \\
\text { Season: summer } \\
\text { Season: autumn } \\
\text { Season: winter } \\
\text { Animcat: steer } \\
\text { Animcat: cow } \\
\text { Animcat: heifer } \\
\text { Farm } \\
\text { Stress }\end{array}$ & $\begin{array}{l}-3.37 \\
-0.887 \\
-0.407 \\
0.417 \\
-1.35 \\
-0.038 \\
-0.727 \\
1^{1} \\
1.05\end{array}$ & $\begin{array}{l}0.458 \\
0.463 \\
0.506 \\
0.395 \\
0.555 \\
0.368 \\
0.410 \\
- \\
0.313\end{array}$ & $\begin{array}{l}<0.0005 \\
0.055 \\
0.421 \\
0.29 \\
0.015 \\
0.92 \\
0.076 \\
- \\
0.001\end{array}$ & $\begin{array}{l}(-4.27,-2.48) \\
(-1.80,0.021) \\
(-1.40,0.585) \\
(-0.357,1.19) \\
(-2.44,-0.262) \\
(-0.760,0.682) \\
(-1.53,0.077) \\
- \\
(0.433,1.66)\end{array}$ \\
\hline Drop & $\begin{array}{l}\text { Intercept } \\
\text { Push } \\
\text { Temp } \\
\text { Farm } \\
\text { Stress }\end{array}$ & $\begin{array}{l}-3.19 \\
0.265 \\
-0.026 \\
1^{1} \\
1.04\end{array}$ & $\begin{array}{l}0.285 \\
0.064 \\
0.012 \\
- \\
0.190\end{array}$ & $\begin{array}{l}<0.0005 \\
<0.0005 \\
0.030 \\
- \\
<0.0005\end{array}$ & $\begin{array}{l}(-3.74,-2.63) \\
(0.139,0.391) \\
(-0.0495,-0.0026) \\
- \\
(0.663,1.41)\end{array}$ \\
\hline Vocl & $\begin{array}{l}\text { Intercept } \\
\text { Tail } \\
\text { Farm } \\
\text { Stress }\end{array}$ & $\begin{array}{l}-1.85 \\
-0.291 \\
1^{1} \\
1.72\end{array}$ & $\begin{array}{l}0.430 \\
0.144 \\
- \\
0.345\end{array}$ & $\begin{array}{l}<0.0005 \\
0.043 \\
- \\
<0.0005\end{array}$ & $\begin{array}{l}(-2.69,-1.01) \\
(-0.572,-0.009) \\
- \\
(1.05,2.40)\end{array}$ \\
\hline Viol & $\begin{array}{l}\text { Intercept } \\
\text { Animcat: steer } \\
\text { Animcat: cow } \\
\text { Animcat: heifer } \\
\text { Plant: } \text { stationary } \\
\text { Farm } \\
\text { Stress }\end{array}$ & $\begin{array}{l}-2.49 \\
-1.04 \\
-1.80 \\
-0.852 \\
0.740 \\
1^{1} \\
1.54\end{array}$ & $\begin{array}{l}0.428 \\
0.434 \\
0.371 \\
0.340 \\
0.277 \\
- \\
0.298\end{array}$ & $\begin{array}{l}<0.0005 \\
0.017 \\
<0.0005 \\
0.012 \\
0.008 \\
- \\
<0.0005\end{array}$ & $\begin{array}{l}(-3.33,-1.65) \\
(-1.89,-0.187) \\
(-2.53,-1.07) \\
(-1.52,-0.186) \\
(0.197,1.28) \\
- \\
(0.954,2.12)\end{array}$ \\
\hline Stress & $\begin{array}{l}\text { Tool } \\
\text { Push } \\
\text { Goad } \\
\text { Animcat: } \text { steer } \\
\text { Animcat: cow } \\
\text { Animcat: heifer } \\
\text { Cweight, } \mathrm{kg}\end{array}$ & $\begin{array}{l}0.0067 \\
0.115 \\
0.042 \\
-0.021 \\
0.194 \\
0.046 \\
-0.0017\end{array}$ & $\begin{array}{l}0.0020 \\
0.040 \\
0.015 \\
0.122 \\
0.099 \\
0.102 \\
0.0006\end{array}$ & $\begin{array}{l}0.001 \\
0.004 \\
0.006 \\
0.86 \\
0.050 \\
0.655 \\
0.008\end{array}$ & $\begin{array}{l}(0.0028,0.011) \\
(0.037,0.193) \\
(0.012,0.072) \\
(-0.261,0.218) \\
(-0.0001,0.387) \\
(-0.154-0.245) \\
(-0.0030--0.0005)\end{array}$ \\
\hline
\end{tabular}

${ }^{1}$ Coefficient constrained to 1 . 


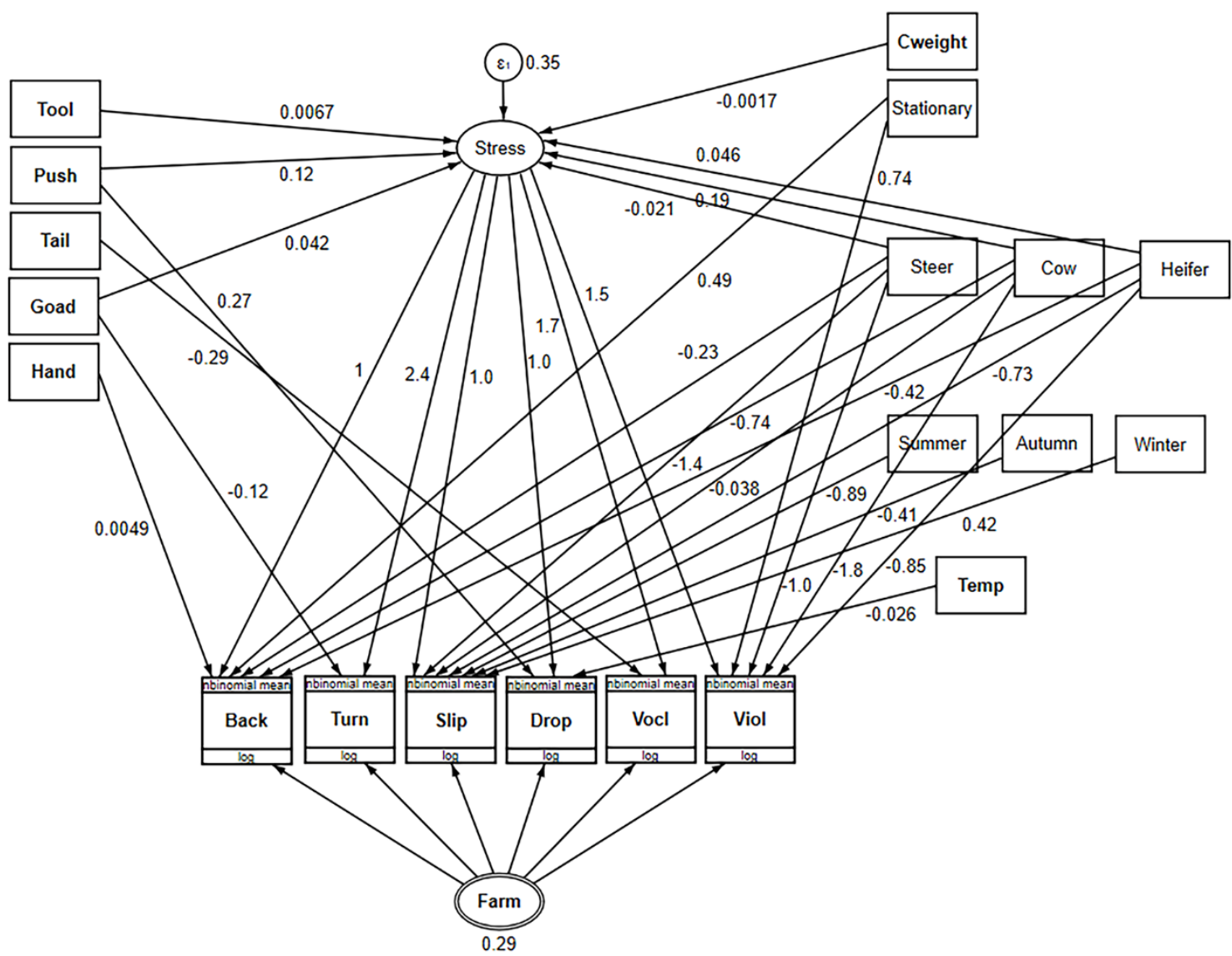

Fig. 1. Final generalised structural equation model. Plain squares denote exogenous variables (stockperson actions to the left and background variables to the right). Squares with additional information are observed endogenous animal behaviour variables (assumed to follow a negative binomial distribution). The plain oval represents the latent endogenous variable Stress, with its error variance. The double oval is a random Farm effect, with its error variance. Arrows represent linear associations with unstandardised coefficients estimated by regression.

The number of backings and violent behaviours (kicking, goring or fighting) differed significantly between the plants, but remaining behaviours could not be shown to differ. Backing and violent behaviours were less common in the mobile plant than in the stationary one, and stress-related behaviours were generally more common if the animal was subjected to more stockperson actions. The incidence risk of backing was 1.6 times lower at the mobile than at the stationary plant $(p<0.0005$; Table 9). The difference between plants was significant in all animal types $(p<0.05$; Fig. 2) and at all carcass weights between quartiles 1 and $3(p<0.05$; Fig. 3$)$. Animals were predicted to display on average $0.015,0.020,0.34$ and 0.12 more backings for every extra hand, tool, push and goad action, respectively ( $p=0.022,0.001,0.006$ and 0.007 , respectively; Table 10; Fig. 4). 
Table 10

Average marginal effects $(\mathrm{dy} / \mathrm{dx})$ of stockperson actions on animal behaviours, estimated by the final generalised structural equation model with stockperson actions and animal behaviours specified as counts $(n=591)$.

\begin{tabular}{|c|c|c|c|c|c|}
\hline $\begin{array}{l}\text { Stockperson } \\
\text { action }\end{array}$ & $\begin{array}{l}\text { Animal } \\
\text { behaviour }\end{array}$ & $\mathrm{dy} / \mathrm{dx}$ & SE & $p$ value & $95 \%$ confidence interval \\
\hline Hand & Back & 0.0145 & 0.0064 & 0.022 & $(0.0021,0.0269)$ \\
\hline Tool & $\begin{array}{l}\text { Back } \\
\text { Turn } \\
\text { Slip } \\
\text { Drop } \\
\text { Vocl } \\
\text { Viol }\end{array}$ & $\begin{array}{l}0.0195 \\
0.0204 \\
0.0010 \\
0.0014 \\
0.0113 \\
0.0045\end{array}$ & $\begin{array}{l}0.0061 \\
0.0075 \\
0.00052 \\
0.00056 \\
0.0058 \\
0.0020\end{array}$ & $\begin{array}{l}0.001 \\
0.007 \\
0.049 \\
0.010 \\
0.051 \\
0.025\end{array}$ & $\begin{array}{l}(0.0076,0.0315) \\
(0.0057,0.0351) \\
(0.000004,0.0020) \\
(0.00035,0.0025) \\
(-0.00007,0.0227) \\
(0.00058,0.0084)\end{array}$ \\
\hline Push & $\begin{array}{l}\text { Back } \\
\text { Turn } \\
\text { Slip } \\
\text { Drop } \\
\text { Vocl } \\
\text { Viol }\end{array}$ & $\begin{array}{l}0.3377 \\
0.3522 \\
0.0177 \\
0.0800 \\
0.1955 \\
0.0780\end{array}$ & $\begin{array}{l}0.1217 \\
0.1414 \\
0.0094 \\
0.0199 \\
0.0992 \\
0.0364\end{array}$ & $\begin{array}{l}0.006 \\
0.013 \\
0.059 \\
0.000 \\
0.049 \\
0.032\end{array}$ & $\begin{array}{l}(0.0992,0.5763) \\
(0.0751,0.6293) \\
(-0.00067,0.0361) \\
(0.0410,0.1190) \\
(0.0011,0.3900) \\
(0.0066,0.1494)\end{array}$ \\
\hline Tail & Vocl & -0.2866 & 0.1662 & 0.085 & $(-0.6123,0.0391)$ \\
\hline Goad & $\begin{array}{l}\text { Back } \\
\text { Turn } \\
\text { Sip } \\
\text { Drop } \\
\text { Vocl } \\
\text { Viol }\end{array}$ & $\begin{array}{l}0.1237 \\
-0.0239 \\
0.0065 \\
0.0091 \\
0.0716 \\
0.0286\end{array}$ & $\begin{array}{l}0.0463 \\
0.0468 \\
0.0036 \\
0.0039 \\
0.0405 \\
0.0144\end{array}$ & $\begin{array}{l}0.007 \\
0.61 \\
0.073 \\
0.021 \\
0.077 \\
0.048\end{array}$ & $\begin{array}{l}(0.0331,0.2144) \\
(-0.1156,0.0678) \\
(-0.00061,0.0136) \\
(0.0014,0.0168) \\
(-0.0077,0.1509) \\
(0.00029,0.0569)\end{array}$ \\
\hline
\end{tabular}

The predicted average number of turnings was 0.020 and 0.35 higher per extra tool and push action, respectively ( $p=0.007$ and 0.013 , respectively; Table 10; Fig. 5). Due to counteracting direct and indirect effects, there was no significant effect of electric-goad actions on turning (Tables 9 and 10; Fig. 6).

The predicted average number of slippings was 0.0010 higher per extra tool action $(p=0.049$; Table 10). The number of slippings also increased with push and goad actions, but the associations were only marginally significant (Table 10). The predicted average number of eliminative behaviour was $0.0014,0.080$ and 0.0091 higher per extra tool, push and goad action, respectively $(p=0.010$, $<0.0005$ and 0.021 , respectively; Table 10 ). The predicted average number of vocalisations increased marginally with tool, push and goad actions, and dropped marginally with tail-twist actions (Table 10; Figs. 7 and 8).

The incidence risk of violent behaviour was 2.1 times lower at the mobile than at the stationary plant ( $p=0.008$; Table 9). The difference between plants was significant in bulls and cows $(p \leq 0.05)$, but not in steers or heifers (Fig. 9), and it was significant at all carcass weights between quartiles 1 and 3 ( $p \leq 0.05$; Fig. 10). The predicted average number of violent behaviours was $0.0045,0.078$ and 0.029 higher per extra tool, push and goad action, respectively $(p=0.025,0.032$ and 0.048 , respectively; Table 10; Fig. 11).

The SEM suggested that Animcat influenced animal behaviours through both indirect and direct effects, that Season influenced slipping behaviour directly, that eliminative behaviour decreased with ambient air temperature, and that higher carcass weights decreased the latent variable Stress, thus indirectly decreasing the numbers of animal behaviours. There were no indications of effects of $\boldsymbol{H o u r}$, Breed or Age. 


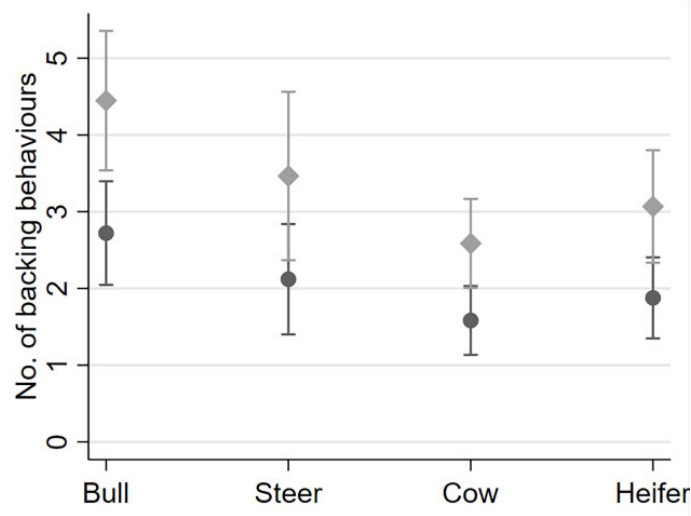

Fig. 2. Predictive margins of Plant and animal type. Number of backing behaviours per animal per $6.08 \mathrm{~m}$ of driveway; black circles $=$ mobile plant; grey diamonds $=$ stationary plant; error bars $=95 \%$ confidence interval.

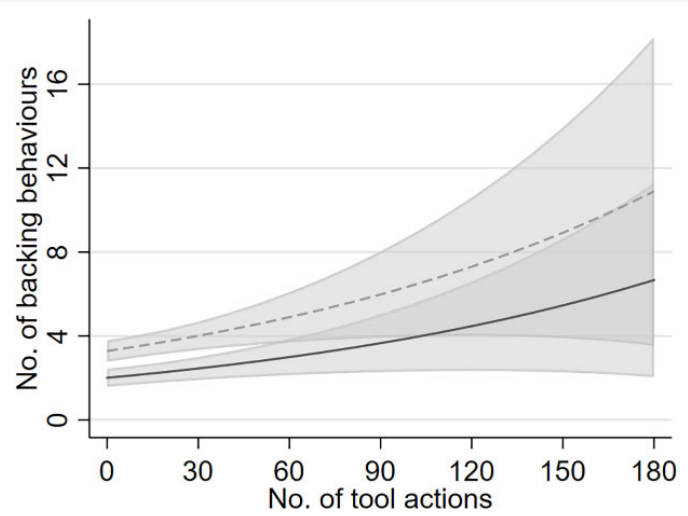

Fig. 4. Predictive margins of Plant and number of stockperson tool actions. Number of backing behaviours per animal per $6.08 \mathrm{~m}$ of driveway;

black solid line $=$ mobile plant; grey dashed line $=$ stationary plant; shaded area $=95 \%$ confidence interval.

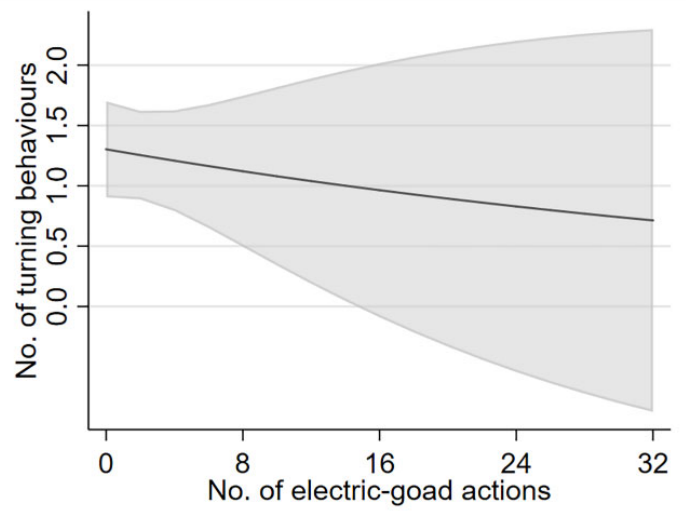

Fig. 6. Predictive margins of number of stockperson electric-goad actions. Number of turning behaviours per animal per $6.08 \mathrm{~m}$ of driveway; shaded area $=95 \%$ confidence interval.

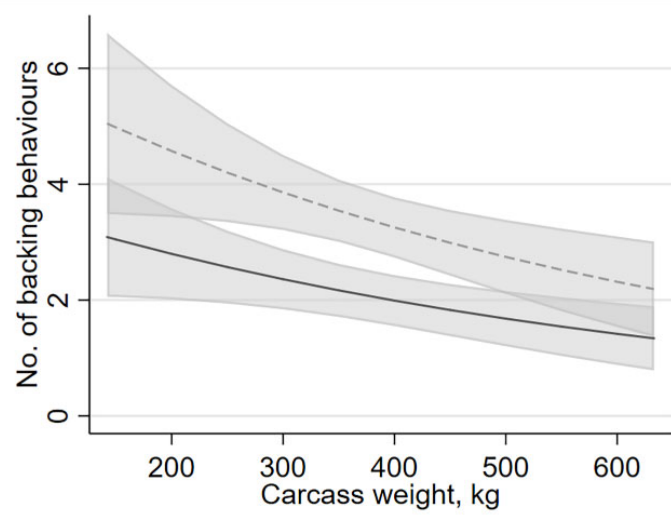

Fig. 3. Predictive margins of Plant and carcass weight. Number of backing behaviours per animal per $6.08 \mathrm{~m}$ of driveway; black solid line $=$ mobile plant; grey dashed line $=$ stationary plant; shaded area $=95 \%$ confidence interval.

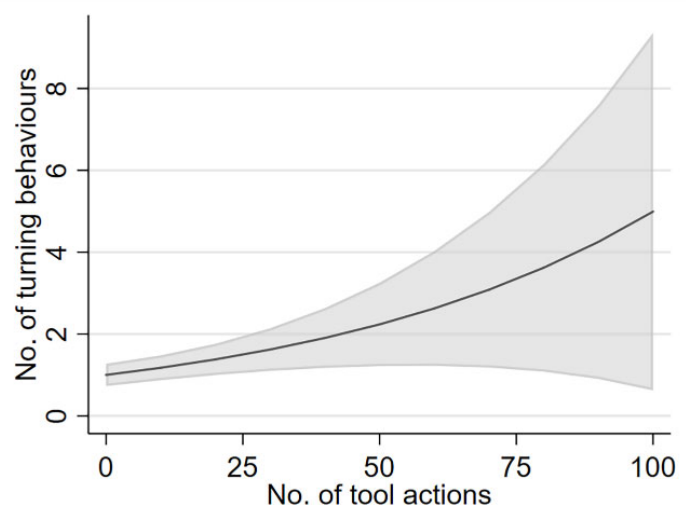

Fig. 5. Predictive margins of number of stockperson tool actions. Number of turning behaviours per animal per $6.08 \mathrm{~m}$ of driveway; shaded area $=95 \%$ confidence interval.

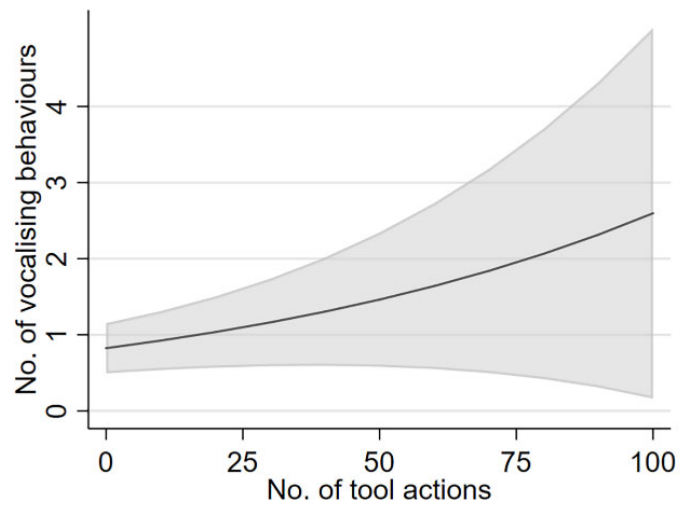

Fig. 7. Predictive margins of number of stockperson tool actions. Number of vocalisations per animal per $6.08 \mathrm{~m}$ of driveway; shaded area $=95 \%$ confidence interval. 


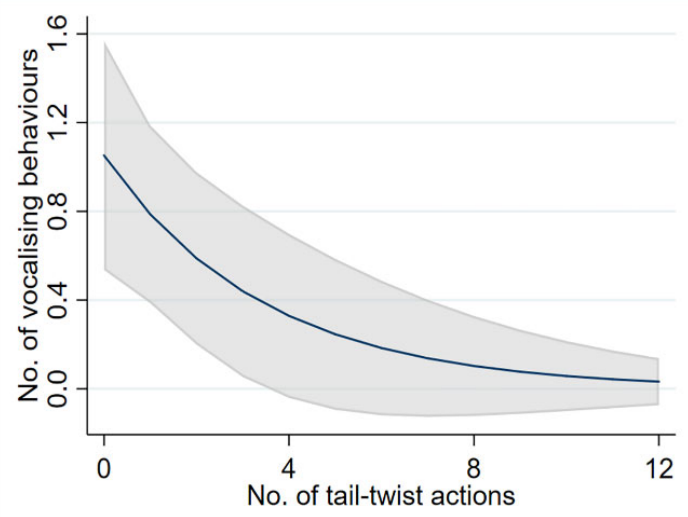

Fig. 8. Predictive margins of number of stockperson tail-twist actions. Number of vocalisations per animal per $6.08 \mathrm{~m}$ of driveway; shaded area $=95 \%$ confidence interval.

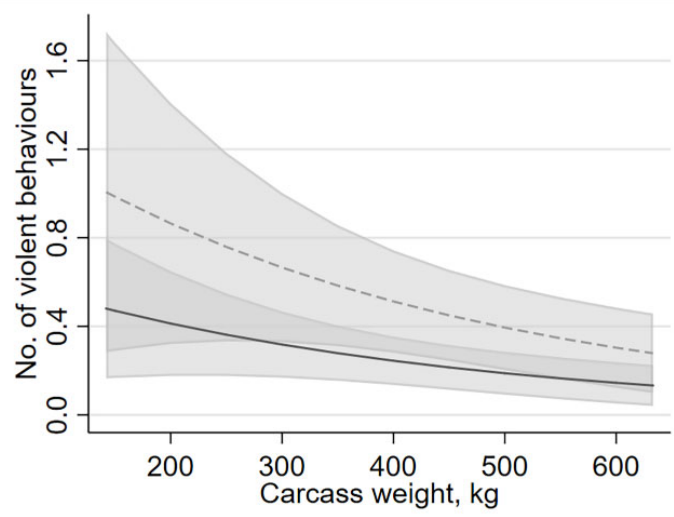

Fig. 10. Predictive margins of Plant and carcass weight. Number of violent behaviours per animal per $6.08 \mathrm{~m}$ of driveway; black solid line $=$ mobile plant; grey dashed line $=$ stationary plant; shaded area $=95 \%$ confidence interval.

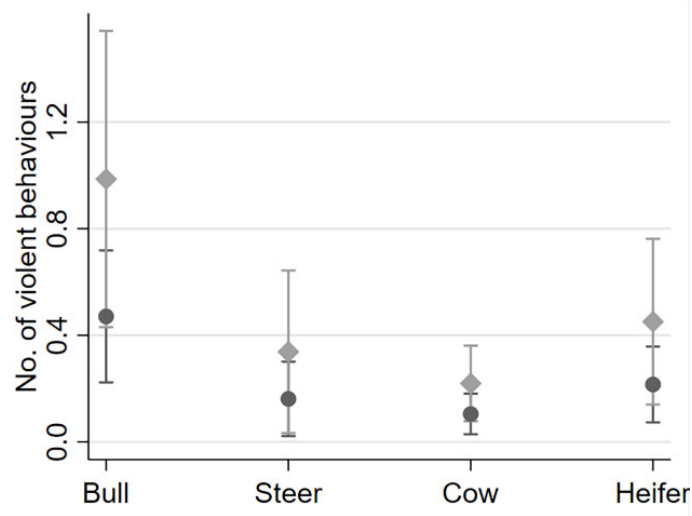

Fig. 9. Predictive margins of Plant and animal type. Number of violent behaviours per animal per 6.08 $\mathrm{m}$ of driveway; black circles=mobile plant; grey diamonds $=$ stationary plant; error bars $=95 \%$ confidence interval.

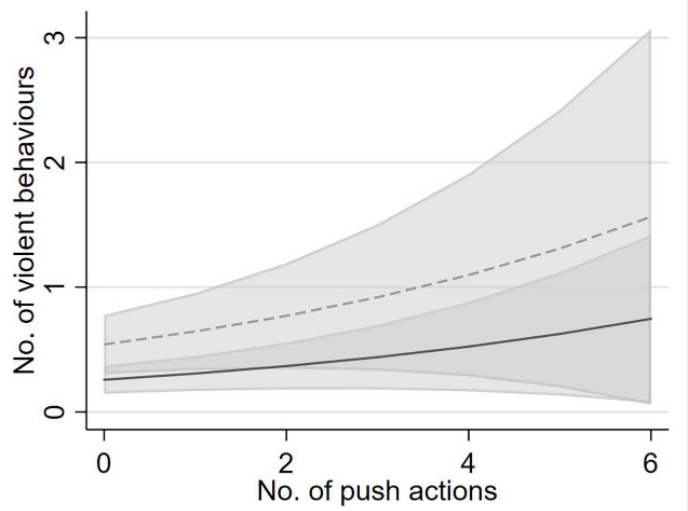

Fig. 11. Predictive margins of Plant and number of stockperson push actions. Number of violent behaviours per animal per $6.08 \mathrm{~m}$ of driveway; black solid line $=$ mobile plant; grey dashed line $=$ stationary plant; shaded area $=95 \%$ confidence interval.

\section{Discussion}

The current study estimated associations between stockperson actions and animal behaviours during pre-slaughter handling of cattle in a mobile plant, comparing with a stationary plant. From our study, it is not possible to draw definite conclusions about differences between mobile and stationary slaughter of cattle in general, since only one plant of each type was studied and these cannot be regarded with certainty as representative of a target population of plants. The comparisons that can be made between mobile and stationary slaughter therefore mainly apply to the two studied plants. Despite this, we wanted to point out some differences and seek explanations for these.

The characteristics of the study animals were in good agreement with the Swedish population of slaughter cattle, although the mobile plant seemed to prioritise beef steers and heifers, and fattening bulls of a slightly lower age than the stationary plant. Just under half of all Swedish cattle slaughtered are of beef or mixed dairy-beef breeds. A large number of different beef breeds are used, with the most common being Charolais, Hereford, Simmental, Limousine, Angus, Highland Cattle and Blonde $d$ 'Aquitaine. The proportion of pure-bred animals of beef breed is small (Svenskt Kött, 2020). The most common dairy breeds are Swedish Holstein and Swedish Red, which together constitute more than $90 \%$ of all dairy cows. Most cows, heifers and steers are grazed during summer months, while 
adult bulls reared for slaughter are usually kept indoors. Swedish beef production includes springcalving suckler cows and their calves. Bulls are usually slaughtered at the age of 18 months and half of them are of beef breed; heifers and steers are slaughtered at on average 28 months and heifers are typically beef breed while most steers are of dairy breed (Svenskt Kött, 2020).

Behaviours that animals display when being stressed, such as baulking, backing, turning around and struggling, tend to complicate handling (Rabaste et al, 2007), which easily increases the risk of rough handling and intensifies animal stress. Atkinson (2009) and Hultgren et al. (2014) found relationships between rough handling and stress-related animal behaviours in Swedish cattle abattoirs. It has also been shown that frequent use of electric goads causes pigs to display stress-related behaviours (Rabaste et al., 2007; Correa at al., 2010). In the present study, we found that stressrelated behaviours were generally more frequent in animals subjected to many handling actions by stockpersons, compared to few such actions, and that associations between stockperson actions and animal behaviours were to some extent mediated by a common (unobserved) quantity which could be regarded as the animal's tendency to display stress-related behaviours or, simply, its stress level.

Some of the animal welfare problems associated with pre-slaughter transportation can be avoided by on-farm slaughter (Hultgren, 2018). By taking the abattoir to the farm and carrying out slaughter in the place where the animals were reared, exposure of the animals to unfamiliar environments, other animals and stockpersons can be prevented. In addition, on-farm slaughter usually means a low line speed, which contributes to a calm and relatively stress-free slaughter (Stocchi et al., 2014). On the other hand, industrial slaughter can have a larger potential for investments to achieve efficient animal handling. Indeed, it may be difficult to carry out slaughter in confined spaces in remote areas, with limited and reliable access to clean water and electricity (Greger, 2007).

In the present study, most animals were not handled at all or handled only a few times and a few of them were subjected to many actions. Similarly, there was a small number of animals that exhibited many stress-related behaviours while most showed only a few such behaviours. However, more than $90 \%$ of the animals were handled actively in the driveway, and almost $80 \%$ displayed one or several stress-related behaviours, which suggests that most animals experienced the passage through the driveway as at least slightly stressful. At both plants, the most commonly occurring action was Tool (49-59\% of animals), usually involving a sorting paddle, and the most common behaviour was Back $(68-85 \%)$.

Ideally, the design of the driveway should facilitate the propulsion of animals for stunning. It should also make it easier for the staff to utilise the animals' natural flight behaviour by placing and moving the body at the adequate distance and at the right angle to the animals. Grandin (1997) argued that solid walls in the driveway are advantageous because they reduce the risk of animals being disturbed by humans, animals or objects alongside the driveway. Bourguet et al. (2011) found distractions in the driveway such as noise, darkness, presence of people and activity to cause handling problems and vocalisation. In this study, the driveway at the mobile plant, in contrast to the stationary counterpart, was temporarily mounted directly on the ground, adapted to the local conditions and with walls made of metal pipes that were only occasionally covered by solid boards. The animals were therefore exposed to potentially disturbing visual impressions through the walls. Despite this, backing was significantly less frequent at the mobile plant than at the stationary one.

A good human-animal relationship has become widely accepted as a criterion for good animal welfare (Welfare Quality $\left.{ }^{\circledR}, 2009\right)$. Attitudes towards animals account for variation in stockperson behaviour towards animals (Hemsworth et al., 1993). It is important for handlers to understand the principles of good human-animal interactions and to have positive attitudes towards the animals (Coleman et al., 2003; Hemsworth, 2003). Training handlers to move animals appropriately can reduce the need for rough handling methods, such as excessive prodding with an electric goad (Grandin, 2010). In the EU, all stockpersons at slaughterhouses must hold a certificate of competence demonstrating their ability to handle the animals (Council Regulation No 1099/2009). Although such a certificate is likely to improve the conditions under which animals are treated, it does not preclude questionable handling actions. Handlers may feel pressured by a high workload and have difficulties to do their job properly due to inadequate building and vehicle designs. They may therefore perceive a loss of control, and feel compelled to take forceful actions that induce or intensify animal stress (Coleman et al., 2012). 
In this study, most animals at the mobile plant were handled by farm staff, for which there are no requirements of special training or competence in this regard. Pushing and tail-twisting were more common at the mobile plant, while the electric goad was more used at the stationary plant. This may be explained partly by the design of the driveway and partly by the stockpersons' preferred working methods. At the mobile plant, the stockpersons often entered the driveway when moving the animals, which rarely happened at the stationary plant. When baulking or being moved forcefully in a singlefile driveway, the animal is more likely to express violent behaviours such as kicking, goring, butting or fighting towards a stockperson inside the driveway. Despite this, violent behaviours were less frequent at the mobile plant than at the stationary one. The fact that most of the animals at the mobile plant were handled by farm staff known to them may have contributed to this difference.

Logically, a longer time in the driveway should give staff the opportunity to perform more handling actions and the animals to display more behaviours. For example, a defective design of a driveway is likely to result in slower passage, more active and forceful handling and more stressrelated animal behaviours. On the other hand, as pointed out by Hultgren et al. (2014), a low line speed can result in fewer stockperson actions and animal behaviours due to lower stress levels, even though the time in the driveway is longer. A slow passage as a result of deliberately low line speed can thus contribute to good animal welfare. Coleman et al. (2012) found that a pressured work situation as a result of a perceived lack of control and lack of time was related to more forceful handling. This leads to the question of whether the frequency of driving actions and animal behaviours should be expressed as raw counts (regardless of time) or as numbers per unit of driveway distance or time, e.g. number of drives per metre or minute. The raw counts probably reflect the total impact on the animals on the observation path and they are also easier to compare with the results from other studies, such as Grandin (1998), Hemsworth et al. (2011) and Hultgren et al. (2014). On the other hand, numbers standardised for distance or time may provide more correct estimates of the incidence risk of a behaviour. In this study, correlations and factor loadings from principal components analysis indicated that standardisation for driveway length was the most informative variant of animal behaviour variables, followed by raw counts.

A total of 14 stockpersons were observed while handling the animals, which may have influenced the estimated effects. Differences in animal handling between different people at the slaughterhouse can be explained by different attitudes towards the work and the animals, knowledge of animal behaviour and skill to handle them, all of which can be expected to vary depending on education, experience and personal orientation. Coleman et al. $(2003 ; 2012)$ showed that staff attitudes to the work and the animals affect animal management. The studies by Coleman and coworkers suggest that it is possible to improve animal handling at slaughter by addressing staff attitudes at various training activities. It has also been suggested that the slaughterhouse management has an important normative role (Grandin, 2013).

The on-farm conditions can be assumed to have varied greatly in many respects, which could also have influenced animal stress levels. Examples of potentially influential farm-related factors were breeding strategies, housing conditions and routines for the care, feeding and handling of the animals, grazing routines and health conditions in the herd. At the mobile plant, the location and direction of the abattoir in relation to the animal housing facilities (affecting driveway length and sunlight), soil conditions and the presence of objects or other disturbances outside the plant and driveway contributed to variation between farms. High noise levels are common in slaughterhouses (Weeks $e t$ al., 2009) and can cause animal stress and make handling difficult. At mobile slaughter, conditions for achieving a low noise level outside the slaughterhouse may be present, which should facilitate the operation. Possibly, however, the absence of a constant, rather high noise level can make the animals more sensitive to occasional sharp sound impressions. At the studied mobile plant, it was noted that loud noise from inside the slaughterhouse sometimes disturbed the animals outside, which may have contributed to violent behaviour. At the stationary plant, the design of on-farm loading facilities and transport conditions contributed with variation. We included a random $\boldsymbol{F a r m}$ effect to account for this variation.

For several reasons, the statistical analysis was challenging. Instead of considering the animal behaviours separately, we chose to combine them in a measurement model, assuming a latent construct that represented the animal's tendency to display stress-related behaviours, or its stress level. The six selected behaviours were judged to be useful indicators of such a construct. However, 
the validity of the measurement model (in terms of internal consistency) could only be assessed while specifying the behaviours as continuous variables. Likewise, the subsequent building of the complete SEM relied on model fit statistics using continuous outcome variables and no random effect (ordinary SEM). In the final model, however, the behaviours were modelled as counts with driveway length as the exposure parameter and the model included a random effect of farm identity (generalised SEM). Due to convergence difficulties, it was not possible to test all exogenous variables and use backward elimination from a full model. Instead stockperson actions were considered first, and then background variables. Nevertheless, to arrive at the final model, paths were added and deleted until convergence was reached and all paths were significant. Despite these difficulties and methodological shortcuts the final model appeared logical and coherent. We have not found any previous publications reporting on stress-related animal behaviour analysed with CFA or SEM.

Direct comparisons of the two slaughter plants are complicated by the fact that the conditions differed in many respects. One explanation for differences between the two plants found in this study may have been that the animals were actually handled in a mobile or stationary slaughter system, which this study was intended to highlight. Other possible explanations are, however, that the premises were differently designed also in other respects, that the animal material differed, that the staff had different possibilities to perform the work, that the line speed and workload were different, that road transport from the farm and overnight lairage only occurred at the stationary slaughterhouse, and - last but not least - that stationary slaughter has a long history of gradual developments, while mobile slaughter is a fairly new phenomenon where one can assume that certain adaptations and adjustments remain (Hultgren, 2018). The mobile plant had been in operation for a little more than a year when the observations started.

The observations of the stationary plant covered only the last part of the driveway into the stun box, not the journey from the farm, nor any longer stay at the abattoir. The impact that the transport itself and lairage at the plant may have had, therefore, was not assessed directly. Nevertheless, it may have affected the animals at the time they were studied. For example, a transient mild stress during loading to the transport vehicle on the farm did not necessarily affect the animals at the plant. On the other hand, rough handling shortly before slaughter may have affected the observed animal behaviour considerably.

We conclude that backing and violent behaviours of cattle when moving them into the stun box are less frequent at the mobile than at the stationary slaughter plant studied, that stress-related behaviours are more frequent in animals subjected to many handling actions by stockpersons, compared to few such actions, and that associations between stockperson actions and animal behaviours are to some extent mediated by a common (unobserved) quantity which could be regarded as the animal's stress level.

\section{Declaration of Competing Interest}

The authors have no conflicts of interest to declare.

\section{Acknowledgements}

The authors wish to thank the two involved slaughter companies for the possibility to carry out the project, especially for the personnel who assisted in various ways in connection with the data collection at handling. Research technicians Anne Larsen and Karin Wallin collected the data and provided valuable input on project implementation. This work was supported through donations from Marie-Claire Cronstedt Foundation and the Swedish Animal Welfare Association. The slaughter companies and financing bodies did not take part in the analysis or interpretation of results.

\section{References}

Acock, A.C., 2013. Discovering Structural Equation Modeling Using Stata, first revised ed. Stata Press, College Station, Texas, USA. 
Angioloni, S., Kostandini, G., Alali, W.Q., O'Bryan, C.A., 2015. Economic feasibility of mobile processing units for small-scale pasture poultry farmers. Renew. Agric. Food Syst. 31, 387-401. https://doi.org/10.1017/S1742170515000319.

Atkinson, S., 2009. Assessing cattle welfare at stunning. Proc. 43rd Congr. Int. Soc. Appl. Ethol., Cairns, Australia, 6-10 July 2009, p. 79. Abstract.

Bench, C., Schaefer, A., Faucitano, L., 2008. The welfare of pigs during transport, in: Faucitano, L., Schaefer, A.L. (Eds.), Welfare of pigs from birth to slaughter. Wageningen Academic Publishers, Wageningen, The Netherlands, pp. 161-195.

Bentler, P.M., 1990. Comparative fit indexes in structural models. Psychol. Bull. 107, 238-246. https://dx.doi.org/10.1037/0033-2909.107.2.238.

Bentler, P.M., Woodward, J.A., 1980. Inequalities among lower bounds to reliability: with applications to test construction and factor analysis. Psychometrika 45, 249-267. https://doi.org/10.1007/BF02294079.

Bourguet, C., Deiss, V., Cohen Tannugi, C., Terlouw, E.M.C., 2011. Behavioural and physiological reactions of cattle in a commercial abattoir: Relationships with organisational aspects of the abattoir and animal characteristics. Meat Sci. 88, 158-168.

Brown, T.A., 2015. Confirmatory Factor Analysis for Applied Research, second ed. Guilford Press, New York, USA.

Browne, M.W., Cudeck, R., 1993. Alternative ways of assessing model fit, in: Bollen, K.A., Long, J.S. (Eds.), Testing Structural Equation Models. Sage, Newbury Park, California, USA, pp. 136-162.

Bunzel-Drüke, M., Böhm, C., Finck, P., Kämmer, G., Luick, R., Reisinger, E., Riecken, U., Riedl, J., Scharf, M., Zimball, O., 2009. "Wilde Weiden”. Praxisleitfaden für Ganzjahresbeweidung in Naturschutz und Landschaftsentwicklung. Working Group on Biological Environmental Protection in the Soest e.V. district (Federal Agency for Nature Conservation; Naturschutz Schleswig-Holstein Foundation; Free State of Thuringia; North Rhine-Westphalia Foundation Nature Conservation, Homeland and Cultural Care), Bad Sassendorf-Lohne, Germany. Report.

Coleman, G.J., McGregor, M., Hemsworth, P.H., Boyce, J., Dowling, S., 2003. The relationship between beliefs, attitudes and observed behaviours of abattoir personnel in the pig industry. Appl. Anim. Behav. Sci. 82, 189-200. https://doi.org/10.1016/S0168-1591(03)00057-1.

Coleman, G.J., Rice, M., Hemsworth, P.H., 2012. Human-animal relationships at sheep and cattle abattoirs. Anim. Welf. 21, Suppl. 2, 15-21. https://doi.org/10.7120/096272812X13353700593329.

Correa, J.A., Torrey, S., Devillers, N., Laforest, J.P., Gonyou, H.W., Faucitano, L., 2010. Effects of different moving devices at loading on stress response and meat quality in pigs. J. Anim. Sci. 88, 4086-4093. https://doi.org/10.2527/jas.2010-2833.

Council Regulation (EC) No 1099/2009 of 24 September 2009 on the protection of animals at the time of killing. Council of Europe.

Cronbach, L.J., 1951. Coefficient alpha and the internal structure of tests. Psychometrika 16, 297-334. https://link.springer.com/article/10.1007\%2FBF02310555.

FAOSTAT, 2017. Food and agriculture data. Rome, Italy: Food and Agriculture Organization of the United Nations. Report. http://www.fao.org/faostat/ (accessed 27 June 2019).

Grandin, T., 1997. The design and construction of facilities for handling cattle. Livest. Prod. Sci. 49, $103-119$. https://doi.org/10.1016/S0301-6226(97)00008-0.

Grandin, T., 1998. Objective scoring of animal handling and stunning practices at slaughter plants. J. Am. Vet. Med. Assoc. 212, 36-39.

Grandin T. (Ed.), 2010. Improving Animal Welfare: A Practical Approach, second ed. CAB International, New York, USA.

Grandin, T., 2013. Making slaughterhouses more humane for cattle, pigs, and sheep. Ann. Rev. Anim. Biosci. 1, 491-512. https://doi.org/10.1146/annurev-animal-031412-103713.

Greger, M., 2007. The long haul: Risks associated with livestock transport. Biosecur Bioterror. 5, 301-311. https://doi.org/10.1089/bsp.2007.0028.

Gwin, L., Thiboumery, A., 2014. Beyond the farmer and the butcher: Institutional entrepreneurship and local meat. J. Agric. Food Syst. Community Dev. 4, 81-96. https://doi.org/10.5304/jafscd.2014.042.007.

Hancock, G. R., Mueller, R.O. (Eds.), 2006. Structural Equation Modeling: A Second Course. Information Age Publishing, Charlotte, North Carolina, USA, p 157.

Hemsworth, P.H., 2003. Human-animal interactions in livestock production. Appl. Anim. Behav. Sci. 81, 18598. https://doi.org/10.1016/S0168-1591(02)00280-0.

Hemsworth, P.H., Barnett, J.L., Coleman, G.J., 1993. The human-animal relationship in agriculture and its consequences for the animal. Anim. Welf. 2, 33-51.

Hemsworth, P.H., Rice, M., Karlen, M.G., Calleja, L., Barnett, J.L., Nash, J., Coleman, G.J., 2011. Humananimal interactions at abattoirs: relationships between handling and animal stress in sheep and cattle. Appl. Anim. Behav. Sci. 135, 24-33. https://doi.org/10.1016/j.applanim.2011.09.007. 
Hultgren, J., 2018. Is livestock transport a necessary practice? Mobile slaughter and on-farm stunning and killing before transport to slaughter. CAB Reviews 13, No. 054. https://doi.org/10.1079/PAVSNNR201813054.

Hultgren, J., Berg, C., Karlsson, A.H., Schiffer, K.J., Algers, B., 2018. On-farm slaughter - ethical implications and prospects, in: Springer, S., Grimm, H. (Eds.), Professionals in Food Chains, Wageningen Academic Publishers, Wageningen, Netherlands, pp. 146-151.

Hultgren, J., Wiberg, S., Berg, C., Cvek, K., Lunner Kolstrup, C., 2014. Cattle behaviours and stockperson actions related to impaired animal welfare at Swedish slaughter plants. Appl. Anim. Behav. Sci. 152, 2337. https://doi.org/10.1016/j.applanim.2013.12.005.

Johnson, R.J., Marti, D.L., Gwin, L., 2012. Slaughter and processing options and issues for locally sourced meat. United States Department of Agriculture, Economic Research Service, Washington D.C., USA, Report No. LDP-M-216-01.

Jöreskog, K.G., Goldberger, A.S., 1975. Estimation of a model with multiple indicators and multiple causes of a single latent variable. J. Am. Stat. Assoc. 70, 631-639. https://www.jstor.org/stable/2285946.

Lambooij, E., Puister-Jansen, L., Graven, W., Bemelman, Y., Hoste, R., 2011. Haalbaarheid mobiel slachthuis en uitsnijderij. Lelystad, The Netherlands: Wageningen UR Livestock Research, Contract No. BO-12.09002-007, Report No. 460.

McDonald, R., 1999. Test theory: a unified treatment. Lawrence Erlbaum Associates, Mahwah, New Jersey, USA.

Oehlert, G.W., 1992. A note on the delta method. Am.Stat. 46, 27-29. https://doi.org/10.2307/2684406.

Rabaste, C., Faucitano, L., Saucier, L., Mormède, P., Correa, J.A., Giguère, A., Bergeron, R., 2007. The effects of handling and group size on the welfare of pigs in lairage and their influence on stomach weight, carcass microbial contamination and meat quality. Can. J. Anim. Sci. 87, 3-12. https://doi.org/10.4141/A06-041.

Rabe-Hesketh, S., Skrondal, A., Pickles, A., 2005. Maximum likelihood estimation of limited and discrete dependent variable models with nested random effects. J. Econom. 128, 301-323. https://doi.org/10.1016/j.jeconom.2004.08.017.

Raussi, S., 2003. Human-cattle interactions in group housing. Appl. Anim. Behav. Sci. 80, 245-262. https://doi.org/10.1016/S0168-1591(02)00213-7.

Skog Eriksen, M., Rødbotten, R., Grøndahl, A.M., Friestad, M., Andersen, I.L., Mejdell, C.M., 2013. Mobile abattoir versus conventional slaughterhouse - Impact on stress parameters and meat quality characteristics in Norwegian lambs. Appl. Anim. Behav. Sci. 149, 21-29. https://doi.org/10.1016/j.applanim.2013.09.007.

Stocchi, R., Mandolini, N.A., Marinsalti, M., Cammertoni, M., Loschi, A.R., Rea, S., 2014. Animal welfare evaluation at a slaughterhouse for heavy pigs intended for processing. Ital. J. Food Safety 3, 54-56. https://doi.org/10.4081/ijfs.2014.1712.

Svenskt Kött, 2020. Homepage. https://svensktkott.se/.

Waiblinger, S., Boivin, X., Pedersen, V., Tosi, M.-V., Janczak, A.M., Visser, E.K., Jones, R.B., 2006. Assessing the human-animal relationship in farmed species: A critical review. Appl. Anim. Behav. Sci. 101, 185242. https://doi.org/10.1016/j.applanim.2006.02.001.

Weeks, C.A., Brown, S.N., Lane, S., Heasman, L., Benson, T., Warriss, P.D., 2009, Noise levels in lairages for cattle, sheep and pigs in abattoirs in England and Wales. Vet. Rec. 165, 308-314.

Welfare Quality®, 2009. Welfare Quality ${ }^{\circledR}$ assessment protocol for cattle. Welfare Quality® Consortium, Lelystad, Netherlands, Contract No. FOOD-CT-2004-506508, European Union. Report. http://www.welfarequality.net/en-us/reports/assessment-protocols/ (accessed 27 June 2019). 